\title{
Successful percentage of action in mandibular block injection training using Fischer's technique
}

\author{
Natrisa Uthophia*, Kirana Lina Gunawan*, Abel Tasman Yuza* \\ *Department of Oral Maxillofacial Surgery Faculty Of Dentistry Universitas Padjadjaran, Indonesia
}

ABSTRACT

Introduction: Injecting a local anaesthetic amongst students is part of the dentistry education in many countries. Mandibular block injection technique used in the Faculty of Dentistry Universitas Padjadjaran is Fischer's technique. The purpose of this study was to determine the success rate based on the average onset and duration of action in mandibular block injection training using Fischer's technique conducted by the $8^{\text {th }}$-semester students of the Faculty of Dentistry Universitas Padjadjaran batch 2008. Methods: The method of this study was a descriptive survey-sampling method used was the purposive sampling technique. Data was obtained through the questionnaires distributed to 100 students who practice injection using Fischer's technique. Anaesthetics used on these injection training was $2 \%$ lidocaine $\mathrm{HCl}$ with epinephrine 1:80,000. Results: The success rate of mandibular block injection using Fischer's technique was 88\% (88 from 100 injections), with an average onset of action was 2.33 minutes and the average duration of action was 194.07 minutes. Conclusion: The percentage of success in injection training with Fischer's technique was high, with appropriate average onset and duration of action by the existing standards.

Keywords: Success, injection training, Fischer's technique.

\section{INTRODUCTION}

Provision of local anaesthesia is the most common and frequent dental care procedure. It is estimated that local anaesthesia is given more than 300 million times annually in the US. ${ }^{1}$

Anaesthesia that is effective for adults'mandibular is block anaesthesia, because in adults, the cortical bone in the buccal part of the premolar and lower molars inhibits the diffusion of the anaesthetic fluid to the apical part of the tooth. Infiltrative anaesthesia is quite effective in the canine area and incisors due to thinner cortical bone and radicular located on the buccal side. $^{2}$
The anaesthesia of the mandibular block which is often performed by the students of Faculty of Dentistry of Universitas Padjadjaran on the mandibular maxillary tooth extraction procedure is anaesthesia of the inferior alveolar nerve block and the lingual nerve with Fischer technique, plus the buccal infiltration anaesthesia on the molar tooth if a molar tooth is to be removed.

An inferior alveolar nerve block anaesthetic has a lower success rate when compared with anaesthesia of the nerve block on the maxilla. Practitioners should accurately inject anesthetic fluid within approximately $1 \mathrm{~mm}$ of the intended nerve for consideration of the mandibular anatomy (bone density). An inferior alveolar nerve block 
anaesthesia has a low success rate due to two factors: (1) anatomical variation from the height of the mandibular foramen on the lingual portion of the ramus and $(2)$ required a considerable penetration depth in the soft tissues, leading to high inactivity. ${ }^{3}$

The success of anaesthesia in mandibular teeth is difficult to obtain consistently. Inferior alveolar nerve block injections are the most common injections of the lower jaw. It was reported that the success rate of inferior alveolar nerve block injection was $80-85 \%$. This low success rate is due to the high density of buccal alveolar plate, limited access to the inferior alveolar nerve, and variations in anatomy. ${ }^{4}$

The injection of local anaesthesiaby dentistry students to each other has been considered as a necessary activity as part of dental education in many countries. Based on a survey conducted by Rosenberg et al. ${ }^{5}$, the majority of dentistry schools in the United States undertook a technique of injecting local anaesthesia through injecting among students before entering clinical practice.

Injection training between students is a routine activity conducted in Faculty of Dentistry Universitas Padjadjaran when students enter the 8 th semester before entering in exodontia. There are several injections of this exercise to test the nerves in the upper jaw and lower jaw. One of them performed an injecting exercise in the lower jaw to block the inferior alveolar nerve and lingual nerve by Fischer technique.

It is expected that with injection training, students will be more capable and ready to conduct injections in patients later. Although these instructional training activities have been routinely performed, no one has examined the picture of success obtained by students during the injection training. The purpose of this study was to determine the success rate based on the average onset and duration of action in mandibular block injection training using Fischer's technique conducted by the $8^{\text {th }}$-semester students of the Faculty of Dentistry Universitas Padjadjaran batch 2008.

\section{METHODS}

The type of this research was a descriptive survey method. Data was obtained by filling out the questionnaire form by sample after injection. The questionnaire form contains questions about injection results, onset of action and duration of action of injection. Population of this research was student of Faculty of Dentistry Universitas Padjadjaran batch 2008. Sampling in this research using purposive sampling method, the sample was 100 students.

The inclusion criterion in this research was the student of $8^{\text {th }}$ grade, batch 2008 Faculty of Dentistry, Universitas Padjadjaran, will enter the clinic of exodontia, in good general health condition, following the injection training of mandibular block anesthesia with Fischer 's technique done among the students were their first injection with Fischer's technique in humans, and willing to be an operator or patient and fill out the questionnaire form provided in this study. The variables in this study were the result of injection, onset of action, and duration of action.

Materials and tools used in this study included: Informed consent form, questionnaire form, stationery, disposable plastic syringe $3 \mathrm{cc} /$ $\mathrm{ml} 23$ gauge needle size with $1 \frac{1}{4}$ inch needle length; the anesthetic drug used was Lidocaine $\mathrm{HCl} 2 \%$ with a 1:80.000 epinephrine mixture in the form of $2 \mathrm{ml}$ ampoule.

The data obtained from the filling out of the questionnaire form was processed simply, based on the comparison of frequency of success and failure of the injection result. The data was presented in the form of simple frequency distribution table accompanied by calculation in the form of percentage and in the form of diagram. The average of onset of action and duration of action was calculated from successful injection results using the average formula for simple data.

\section{RESULTS}

The results obtained from the questionnaires by 100 samples from students of the $8^{\text {th }}$ semester of batch 2008 Faculty of Dentistry Universitas Padjadjaran. Table 1 shows the calculated data obtained from the questionnaire. The result of data calculation obtained from questionnaires resulted that there were total 100 injection, injection that did not succeed were 12 , while that there were 88 with total onset of action 205.75 minutes and total duration of action 17079 minutes. 
Table 1. Result of data calculation

\begin{tabular}{cccc}
\hline $\begin{array}{c}\text { Result of } \\
\text { injection }\end{array}$ & Frequency & $\begin{array}{c}\Sigma \text { onset of } \\
\text { action } \\
\text { (minutes) }\end{array}$ & $\begin{array}{c}\Sigma \text { duration } \\
\text { of action } \\
\text { (minutes) }\end{array}$ \\
\hline Successful & 88 & 205.75 & 17079 \\
Unsuccessful & 12 & - & - \\
\hline Total & 100 & 205.75 & 17079 \\
\hline
\end{tabular}

Table 2. Percentage of injection result with Fischer's technique

\begin{tabular}{ccc}
\hline Results of injection & Frequency (f) & Percentage (\%) \\
\hline Successful & 88 & 88 \\
Unsuccessful & 12 & 12 \\
\hline Total & 100 & 100 \\
\hline
\end{tabular}

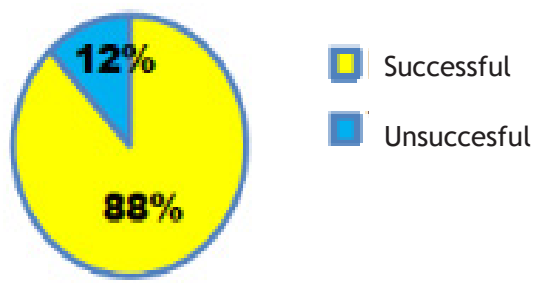

Figure 1. Percentage of injection results with Fischer's technique

Based on Table 2 can be seen that from 100 injections by Fischer's technique, the results of 88 samples or $88 \%$ were successful and 12 samples or $12 \%$ were unsuccessful.

Based on the data obtained from the results of the study, the samples that have successful injection results of Fischer's technique were 88 . The amount of data entered to calculate the average onset of action and the average duration of action of injection was 88 pieces.

From Table 1 can be seen that from 88 successful injections, obtained total onset of action 205.75 minutes and with the above calculation, the average onset of action was 2.33 minutes. This was the average duration of action counted of 88 successful injections. From Table 1 can be seen that from 88 successful injections, obtained total duration of action 17079 minutes and with the above calculation obtained average duration of action was 194.07 minutes.

\section{DISCUSSION}

Based on the results of this study obtained a total of 100 injections with Fischer's technique conducted among students. Based on data from Table 1 can be seen that out of a total of 100 injections, $88(88 \%)$ injection was successful and $12(12 \%)$ injection was unsuccessful. The success rate of injection of the mandibular block obtained in this study was consistent with the results of other studies on injection of the mandibular block, another study of successful injection of the mandibular block shows that the success rate of the mandibular block is about $70-90 \%$.

Other results showed that the success rate of injection of inferior alveolar nerve block or mandibular block varies depending on the technique used. Existing data indicate that inferior alveolar nerve block injection with indirect technique has 15\% ineffectiveness in cases and with direct technique, ineffectiveness between $13-29 \%$ of cases. ${ }^{6}$ The success rate of inferior alveolar nerve block aenesthesia is $80 \%$ to $85 \%$ even if it is done correctly. ${ }^{7}$

Research conducted by Zanette et al. ${ }^{8}$ showed that the failure rate of mandibular block anaesthesia with Gow-Gates technique was $16.6 \%$ and the failure rate of mandibular block with Kenneth Reed technique was $23.3 \%{ }^{8}$ A study by Todashki et al. ${ }^{10}$ on the success rate of inferior alveolar nerve block anesthesia showed that the success rate of IANB injecting technique was $70 \%$ (done by $10^{\text {th }}$ semester students) and $90 \%$ (performed by the resident of the maxillofacial surgery section), the study was performed in 20 patients. Although mandibular block anesthesia performed by an experienced dentist, will result in a good mandibular block of about $85 \%$. Block anaesthesia may fail due to anatomical differences in each individual. ${ }^{10}$

Injections with the Fischer's block technique block 2 nerves: the inferior alveolar nerve and the lingual nerve. Usually in the injection of the mandibular block, the most frequently missed anesthetized nerve is the inferior alveolar nerve. The cause of anaesthesia of inferior alveolar nerve block defects ${ }^{4}$ cannot find a bony landmark with a needle, cannot direct the needle properly because of a hard tissue in pterygomandibular space, the patient's tongue is too large, raised to the posterior, as well as in patients who are unable to pass their lid on a passive basis, the difficulty of determining anatomy due to posterior teeth has been lost and there has been considerable resorption, the 
needle is curved when drawn. This is a sign that the operator is difficult to manipulate the needle while inside the tissues, injecting the anaesthetic fluid down too (under the mandibular foramen), injecting the anesthetic fluid too far into the anterior (lateral) of the ramus, and innervation accessory of the mandibular tooth.

Failure of local anaesthesia can be caused by various factors. The important thing to be noticed by the operator is to identify the cause of the failure. Many authors linked the failure of anaesthesia to a lack of knowledge or experience from practitioners. ${ }^{4}$ Based on the data, after calculating the average of onset of action and duration of action by using the average formula for simple data, the average of onset of action in this research was 2.33 minutes and the average duration of action in this research was 194.07 minutes.

This study used a $2 \%$ lidocaine $\mathrm{HCl}$ anaesthetic drug with a 1:80.000 epinephrine mixture provided in the form of $2 \mathrm{ml}$ ampoule. The average onset of action and duration of action according to the information obtained from the literature on the onset of action and duration of action from lidocaine $\mathrm{HCl}$ with epinephrine mixture. Lidocaine $\mathrm{HCl}$ has a rapid onset of action, which is 2-3 minutes and the duration of action of lidocaine $\mathrm{HCl}$ with the addition of a vasoconstrictor is 120-300 minutes in soft tissue. ${ }^{1,11}$ The onset of action and duration of action of the anesthetic fluid may vary.

In general, the lower the pKa of the anaesthetic fluid the more rapid the onset of action. Also, the higher the lipid solubility level of an anesthetic fluid the faster the onset of action. The duration of action of an anaesthetic fluid is affected by the diffusion in which the anaesthetic fluid is deposited, followed by redistribution through the tissues, thus blood flow is an important factor. Therefore, the total dose, lipid solubility and the use of vasoconstrictors affect the duration of action of anaesthetic fluid. ${ }^{12}$

\section{CONCLUSION}

The percentage of success in injection training with Fischer's technique was high, with appropriate average onset and duration of action by the existing standards.

\section{REFERENCES}

1. Malamed SF. Handbook of local anesthesia $5^{\text {th }}$ ed. St. Louis: Mosby. 2004.

2. Baart JA. Local anaesthesia in the lower jaw. In local anaesthesia in dentistry. London: Wiley-Blackwell; 2009. p. 72-86.

3. Malamed SF. Handbook of local anesthesia $6^{\text {th }}$ ed. St. Louis: Mosby. 2012.

4. Yadav P, Kumar VR. Evaluation of local anaesthetic failures in dental practice.J Int Oral Health. December 2010;2 (Issue-4):15-21.

5. Rosenberg $M$, Orr DL, Starley ED, Jensen DR. Student-to - Student Local Anesthesia Injections in Dental Education: Moral, Ethical, and Legal Issues. J Dent Educ 2009 Jan;73(1):127-32.

6. Palti DG, almeida $C M$, rodrigues $A D C$, andreo $J C$, lima JEO. Anesthetic technique for inferior alveolar nerve block: A new approach. J Appl Oral Sci. 2011;19(1):11-5.

7. Kaufman $E$, Weinstein $P$, Milgrom P. Difficulties in achieving local anesthesia. J Am Dent Assoc 1984;108:205-8.

8. Malamed SF. In Handbook of Local Anesthesia 5th ed. 2004. United States of America: MosbyYear Book Inc.

9. Zanette G, Manani G. Facco E, Mariuzzi. Comparison between two regional anaesthesia techniques performed by inexperienced operators: the Gow- Gates Block versus the Kenneth Reed Block. SAAD Digest 2011;27:8-15.

10. Todashki HH, Rahmati AH. Success rate of 10 th semester dental students of Tehran University of Medical students in infra alveolar nerve block injection technique. J Dent Medic 2009;21(4):285-9.

11. Baart JA, Brand HS. Local Anesthesia in Dentistry. United Kingdom: Blackwell Publishing Ltd. 2009

12. Lipp MDW. Local anesthesia in dentistry. Translated from the german text into the english language by mark coldwell et al. Illinois: Quintessence Publishing Co. Inc. Carol Stream. 1993.

13. Frankhuijzen AL. Pharmacology of local anaesthethics. In local anaesthesia in dentistry. Baart JA, Brand HS (eds). United Kingdom: Wiley-Blackwell Publishing Ltd. 2009. p. 31-41. 